\title{
Os usos do individualismo por James Buchanan *
}

\author{
Eduardo Angeli **
}

\begin{abstract}
Resumo
O artigo procura apresentar a interpretação e aplicação oferecidas por James Buchanan para o individualismo em Economia. Para isso, após uma breve introdução, discutem-se algumas interpretações e usos do homem econômico existentes na literatura econômica. Após isso, apresentam-se tanto a abordagem crítica de Buchanan para o conhecimento convencional da Economia como teoria da escolha, quanto a defesa feita por ele de um tipo particular de individualismo como uma estratégia adotada pelo economista que realiza uma análise institucional comparativa. Por fim, discute-se o individualismo normativo de Buchanan.
\end{abstract}

Palavras chave: Individualismo; Homem econômico; James Buchanan (1791-1868); Constitutional Economics.

\begin{abstract}
James Buchanan's uses of individualism

The article aims to present the interpretation and application offered by James Buchanan for individualism in Economics. In order to achieve this goal, some interpretations and uses of the economic man existing in the economic literature are discussed. We then present Buchanan's critical approach to conventional knowledge of Economics as a theory of choice. We also present his defense of a particular type of individualism as a strategy adopted by the economist who performs a comparative institutional analysis. Finally, we discuss Buchanan's normative individualism.
\end{abstract}

Keywords: Individualism; Economic man; James Buchanan (1791-1868); Constitutional Economics.

JEL B20, B29, B31.

\section{Introdução}

James Buchanan (1919-2013) foi um dos mais importantes economistas do século XX. Laureado com o Prêmio em memória de Alfred Nobel em 1986, Buchanan ficou conhecido como um dos principais nomes associados ao surgimento e consolidação da Public Choice e da Constitutional Economics. Sua vasta obra cobriu diferentes campos do conhecimento econômico, indo das finanças públicas à metodologia da Economia e à História do Pensamento Econômico. Tal fato produz um desafio de sistematização e interpretação de sua contribuição, o que serve de motivação inicial para o presente artigo.

Boettke (1998) e Boettke e Coyne (2005) explicitam que a inserção de Buchanan no debate sobre o endividamento público durante o domínio do keynesianismo ortodoxo, e sua

* Artigo recebido em 2 de abril de 2016 e aprovado em 7 de abril de 2018.

** Professor do Departamento de Economia da Universidade Federal do Paraná (UFPR), Curitiba, PR, Brasil. E-mail: eduardoangeli@hotmail.com. O autor agradece a David Dequech, Ricardo Feijó, Fabio Barbieri, Mauricio Coutinho e Rogerio Pereira de Andrade, bem como aos pareceristas anônimos da Economia e Sociedade, por valiosas críticas e sugestões, eximindoos de erros e omissões remanescentes. $\mathrm{O}$ autor agradece também à Capes e ao CNPq pelo apoio financeiro. 
crítica à teoria das finanças funcionais ${ }^{1}$ e à economia do bem-estar, obrigaram-no a repensar os pilares da ciência econômica, em particular no que se refere ao individualismo.

Segundo o próprio Buchanan, existe uma unidade subjacente à trajetória de seu pensamento que caminhou de questões envolvendo a crítica à economia do bem-estar e à teoria das finanças funcionais, até os fundamentos microeconômicos, em particular com relação ao conceito de custo de oportunidade, e a filosofia social. De acordo com ele (1986a), a coerência existente em seu trabalho é resultado, em primeiro lugar, do seguimento de uma mesma opção metodológica e, em segundo lugar, da aceitação das consequências normativas a que tais opções conduziam ${ }^{2}$. Segundo ele, essa opção metodológica passa pela própria definição do objeto de sua investigação, e a maneira com que a conduz:

[T] he ideas that capture my attention are those that, directly or indirectly, explain how freely choosing individuals can secure jointly desired goals. The simple exchange of apples and oranges between two traders - this institutional model is the sharing point for all that I have done. Contrast this with the choice between apples and oranges in the utility-maximizing calculus of Robinson Crusoe. The second model is the starting point for most of what most economists do (Buchanan, 1986a, p. 26-27).

A melhor compreensão da obra de Buchanan passa pela avaliação de que sua contribuição foi derivada dos desdobramentos explorados de influências por ele recebidas, em particular, a tradição italiana de finanças públicas e Wicksell. Da tradição italiana, especialmente de De Viti de Marco, Puviani e Montemartini, a extensão do conceito de homem econômico para o campo das decisões tomadas no campo político. De Wicksell, a intenção de não negar as conclusões normativas de suas teorias e ideia de se adotar uma regra de unanimidade para a política fiscal e a atuação do governo ${ }^{3}$. Como afirma o próprio Buchanan (1986b, p. 456), em Wicksell "we find (...) all three of the constitutive elements that provide

(1) A Teoria das Finanças Funcionais é devida à contribuição de Abba Lerner. Segundo Colander, "If]unctional finance is a policy in which government fiscal policy, its spending and taxing, its borrowing and repayment of loans, its issue of new money and its withdrawal of money, shall all be taken with an eye only to the results of these actions on the economy" (Colander, 1997, p. 258). Ainda de acordo com Colander, Lerner radicalizou as proposições do keynesianismo do início dos anos 1940, ao argumentar que, na perspectiva keynesiana, "deficits and debt do not matter; what matters is the deficit's effect on the level of employment and inflation" (Colander, 1997, p. 259).

(2) Em entrevista de 1987 disponível em: https://mises.org/library/interview-james-buchanan (Acessado em: 21 mar. 2016), Buchanan afirma: "I have never been especially concerned about making a sharp dividing line between what is positive and what is normative. I don 't consider myself a scientist whose task is discovering a reality that somehow exists independently of me". Na mesma época, ele criticava o descolamento da preocupação dos economistas com a relevância prática de suas pesquisas, bem como com a suposta neutralidade por eles buscada: "economists of the 1980s are illiterate in basic principles of their own discipline (...). Their motivation is not normative; they seem to be ideological eunuchs. Their interest lies in the purely intellectual properties of the models with which they work, and they seem to get their kicks from the discovery of proofs of propositions relevant only for their own fantasy lands" (Buchanan 1986b, p. 46).

(3) A respeito da tradição italiana de finanças públicas, em particular do final do século XIX e início do XX, bem como da abordagem de Wicksell para as finanças públicas, com particular atenção aos desenvolvimentos que levaram à Public Choice, ver Medema (2009, cap. 4). 
the foundations of this theory [Public Choice]: methodological individualism, Homo economicus, and politics-as-exchange"4.

Com o propósito de facilitar a compreensão e oferecer uma interpretação da contribuição de Buchanan, o artigo busca apresentar os usos do individualismo e do homem econômico feitos por ele. Para isso, após esta seção introdutória, a seção 1 examina a construção teórica chamada de homem econômico, a seção 2 apresenta como Buchanan critica a visão convencional de economia como teoria da escolha, a seção 3 discute a utilização do homem econômico por Buchanan e suas consequências teóricas, a seção 4 trata do individualismo normativo de Buchanan, seguindo-se as considerações finais.

\section{Tipos de homem econômico}

Para que se possa avaliar melhor os usos do individualismo por Buchanan e sua relação com a corrente principal da profissão, é conveniente que se faça uma breve discussão a respeito do homo economicus.

O homo economicus tem sido utilizado de duas maneiras ao longo da história do pensamento econômico, segundo Robbins (1932, cap. 4). A primeira delas, por ele associada a nomes como Gossen, Jevons e Edgeworth, assume postulados psicológicos hedonistas para caracterizar o comportamento do homem em suas construções teóricas. É o que Fonseca (1990), ao comentar este texto de Robbins, chama de "homem econômico de tipo psicológico", versão que destaca a motivação estritamente egoísta de toda ação humana.

Segundo a interpretação de Robbins (1932), contudo, tal identificação do homem econômico com motivos estritamente egoístas e hedonistas - uma máquina de prazer e dor foi um evento incidental no desenvolvimento da economia pós-revolução marginalista. ${ }^{6}$ Segundo o autor, os desenvolvimentos feitos pela escola austríaca, e posteriormente encampados pelo restante da profissão, teriam provado que pressupostos psicológicos eram desnecessários ${ }^{6}$.

(4) Sobre o processo de constituição da Public Choice e o papel institucional de Buchanan, ver Buchanan (1992c); Boettke e Marciano (2015); Wagner (2004) e Medema (2009, cap. 6).

(5) "IT]he hedonistic trimmings of the works of Jevons and his followers were incidental to the main structure of a theory which - as the parallel development in Vienna showed - is capable of being set out and defended in absolutely non-hedonistic terms" (Robbins, 1932, p. 86). Segundo Kirzner (1960, cap. 3), "[w]riters such as Bagehot, Lowe, Cunningham, and Edgeworth, who more or less openly held self-interest to be "the first principle of pure economics," were simply carrying on the received tradition" (Kirzner, 1960, p. 59). Ou seja, a adoção de indivíduos egoístas em economia já existia antes da revolução marginalista. Blaug (1992, parte 2, cap. 1) identifica o nascimento do homem econômico no texto de Stuart Mill publicado em 1836, On the Definition of Political Economy. Kirzner chega a nomear a visão de economia que emerge de Stuart Mill (e Bailey) como "ciência da avareza". Sobre o papel do homem econômico no método de Stuart Mill, ver Mattos (2004).

(6) De acordo com Hargreaves-Heap (2008) e Fonseca (1990), o que prevalece na teoria econômica contemporânea, assim como já no tempo de Robbins, é o homem econômico de tipo lógico: "[a]gents are (...) regarded as self-interested, in the looser sense that they are moved to satisfy whatever preferences they happen to haven" (Hargreaves-Heap, 2008, p. 700). Por outro lado. Sen (1988, cap. 1) discorda de que o egoísmo não seja uma hipótese subjacente à maior parte da teoria econômica. Segundo ele, "it is fair to say (...), the assumption of purely self-interested behaviour remains the standard one in economics, providing the behavioural foundation of standard economic theory and policy analysis, and the basis of much of what is taught to students of economics" (Sen, 1988, p. 17, n. 12). No contexto desta citação de Sen, subjacente está uma noção de que o auto-interesse, ao contrário do que consta em Hargreaves-Heap (2008), é egoísta. 
Eduardo Angeli

Ele traz à tona, então, o segundo tipo de homem econômico, qual seja, o "homem econômico de tipo lógico", nas palavras de Fonseca (1990). Aqui, abre-se mão do postulado do egoísmo e do hedonismo desenfreado para se colocar ênfase sobre a racionalidade da escolha, a maneira (racional) de se alcançar determinados fins, independentemente de quais sejam. Nessa ótica, por definição o indivíduo busca seu interesse próprio (que agora possui um sentido bastante amplo), independentemente de qual seja ele, e atinge a maximização de sua utilidade subjetiva, inclua ela ou não, a felicidade de terceiros, o progresso da nação, a preservação da natureza, etc.

Nesse cenário, segundo Amartya Sen, racionalidade e escolha racional assumem papel central e sentido especial, vinculadas à existência de consistência internas. Além disso, ele diz:

A person's choices are considered "rational" in this approach if and only if these choices can all be explained in terms of preference relation consistent with the revealed preference definition, that is, if all his choices can be explained as the choosing of "most preferred" alternatives with respect to a postulated preference relation (Sen, 1977, p. 323, grifo no original).

Retornando a Robbins, ele explica:

The fundamental concept of economic analysis is the idea of relative valuations; and, as we have seen, while we assume that different goods have different values at different margins, we do not regard it as part of our problem to explain why these particular valuations exist. We take them as data. So far as we are concerned, our economic subjects can be pure egoists, pure altruists, pure ascetics, pure sensualists or - what is much more likely — mixed bundles of all these impulses (Robbins, 1932, p. 87).

Tal concepção de homem econômico está vinculada à proposta de Robbins sobre a própria definição da ciência econômica. De acordo com ele:

The economist studies the disposal of scarce means. He is interested in the way different degrees of scarcity of different goods give rise to different ratios of valuation between them, and he is interested in the way in which changes in conditions of scarcity whether coming from changes in ends or changes in means - from the demand side or the supply side - affect these ratios. Economics is the science which studies human behaviour as a relationship between ends and scarce means which have alternative uses (Robbins, 1932, p. 15).

Como transparecerá ao longo das próximas seções (e também argumentado por Kirchgässner, 2014), pode ser argumentado que o homem econômico de que tratava Buchanan ao longo do desenvolvimento de sua agenda de pesquisa é compatível com o que acima foi chamado de homem econômico de tipo psicológico, na medida mesmo em que o autor se afastava da definição robbinsiana convencional de economia. Contudo, em Buchanan este tipo psicológico de homem econômico é utilizado com um propósito distinto do de autores como 
Stuart Mill, Jevons e Edgeworth, qual seja, construir uma análise institucional comparativa robusta, como interpretam Leeson e Subrick (2006).

\section{Buchanan e a crítica da economia convencional como teoria da escolha}

James Buchanan, em artigo publicado em 1964, perguntou-se o que os economistas deveriam fazer, qual seu papel distintivo dentre tantos diversos campos do saber. Para responder a este questionamento, retornou a Adam Smith e sua ideia de uma propensão natural à troca existente nos homens, para argumentar que o trabalho do economista deveria ser uma reflexão sobre os processos de troca como meios de relacionamento entre os indivíduos, o comportamento nestas relações e as instituições e estruturas que emergem a partir desta propensão. Ou seja, na perspectiva de Buchanan, a partir de sua leitura de Smith, a economia é a teoria dos mercados, ciência das trocas e da emergência dos ambientes e instituições que surgem delas ${ }^{7}$. Desse ponto de vista, a proposta convencional de que ela seja a ciência que estuda a alocação de recursos escassos entre fins alternativos é um desvirtuamento de seu propósito original e daquilo defendido por Buchanan ${ }^{8}$.

Buchanan (1964, 1994) enxergou na própria definição convencional de ciência econômica e na ênfase no problema da escolha, na decisão alocativa face à escassez, um deslocamento daquilo que seria o correto assunto da economia tal como proposto por Adam Smith. Isso faz com que, ao invés de terem como objeto de estudo um tipo de manifestação da atividade humana e os arranjos institucionais que emergem a partir dela, os economistas procurem resolver problemas tecnológicos ou de engenharia econômica. Em outras palavras, ele coloca, ao invés de construírem uma "teoria dos mercados", os economistas têm feito avançar uma "teoria da alocação de recursos", e, sob tal visão, "our subject field is a problem or set of problems, not a characteristic form of human activity" (Buchanan, 1964, p. 30). Para o norte-americano, os economistas erram o alvo ao colocar sua preocupação sobre o processo de escolha de recursos escassos entre fins alternativos, ao invés de se concentrarem na construção de "a generalized understanding of the complex set of exchange relationships" (Buchanan, 1994, p. 473).

Sob tal perspectiva, a famosa analogia contada pelos economistas do náufrago Robinson Crusoé como representando o homem econômico é falsa, ao menos até a entrada em cena de Sexta-Feira. O problema econômico, como entendido por Buchanan (1964), não está na alocação de recursos escassos entre fins alternativos que o solitário Crusoé deve levar

(7) Como afirma Wagner, "[t]o Buchanan the central model of economics is exchange and not rational choice" (Wagner, 1987, p. 16)

(8) Nesse sentido, a recuperação que Buchanan realizou de Smith se aproximou das "novas leituras" smithianas que têm sido feitas nas últimas décadas, de que fala Cerqueira (2005). Segundo ele, "o Adam Smith que vem emergindo dessa tentativa de reconstituição do contexto de produção e recepção de sua obra é certamente distinto da figura rotineiramente imaginada pelos economistas. Ao invés de seguir tratando-o como mais um estudioso dos mecanismos de alocação de recursos através da fixação de preços relativos, trata-se de entendê-lo como um pensador preocupado em refletir sobre as maneiras como o auto-interesse e a sociabilidade podem combinar-se para tornar a sociedade comercial mais próspera e virtuosa" (Cerqueira, 2005, p. 194, grifo no original). 
adiante, mas sim no relacionamento associativo simbiótico entre ele e Sexta-Feira. Assim, a atenção do economista deveria estar sobre o processo de troca e de associação benéfica entre os indivíduos envolvidos por certo conjunto institucional, não na escolha individual (ou, por agregação ou antropomorfismo, coletiva).

O alerta de Buchanan $(1949,1964)$ passa pela constatação de que, com o tipo convencional de preocupação em mente, os economistas não são capazes de discernir de quem é a decisão de maximização: indivíduos, comunidade, igreja, sociedade, etc., ou seja, sem poder estabelecer o limite de quais unidades maximizam algo, acabam caindo, sem perceber, na armadilha da agregação vazia de significado. Segundo o autor, mesmo economistas de cunho liberal e defensores do individualismo, como Knight, Friedman e o próprio Robbins, poderiam tentar se safar dessa dificuldade dizendo que a sociedade que resolve seu problema econômicoalocativo deve ser entendida como um grupo de indivíduos que se organizou e concordou em resolver seu problema econômico de determinada maneira; falhariam, porém, por não conseguirem solucionar a questão de como se define a função social de bem estar, nem de como tal arranjo ou acordo é alcançado.

Em Buchanan (1964, 1986b) também é argumentado que o entendimento da ciência econômica como o estudo da alocação de recursos escassos entre fins alternativos, com a ênfase na maximização de determinada função objetivo, faz com que os economistas acabem se engajando em meros problemas computacionais, tornando a economia um simples ramo da matemática aplicada; a diferença entre a economia e a engenharia residiria, assim, no momento de revelação e disponibilidade da função a ser maximizada. Além disso, em sua interpretação, a ciência da escolha se confronta com um paradoxo: a partir de quando a função de utilidade do indivíduo é conhecida, o problema de maximização poderia ser resolvido por um computador, e a escolha se tornaria puramente mecânica; nesse caso, não há escolha propriamente dita entre diferentes alternativas, e um computador poderia resolver todo o problema de um indivíduo que conheça sua função utilidade. A escolha robbinsiana seria, sob tal prisma, um deslocamento do problema econômico.

Ao invés de proporem a regulação e controle de preços, quantidades e práticas tipicamente concorrenciais, os economistas deveriam adotar, segundo ele (Buchanan, 1969), o que ele chama de "política Smithiana", caracterizada pela ênfase na preocupação de se aumentar a possibilidade de trocas mutuamente benéficas e exploração de oportunidades de ganhos, além da melhoria do grau de coordenação entre os indivíduos, através do funcionamento "cristalino", por exemplo, do sistema de preços, bem como a existência de um arcabouço institucional que faria com que o comportamento individual pudesse também promover o interesse alheio como consequência não-intencional.

\section{Buchanan e a adoção do homem econômico como estratégia para a teorização econômica}

Como explicam Boettke e Coyne (2005), há, na economia de Buchanan, dois níveis de análise: o pré-constitucional, em que a atenção está posta sobre as regras a serem adotadas, e a 
pós-constitucional, em que o foco recai sobre as estratégias e o comportamento dos indivíduos dentro das regras pré-determinadas, entendidas como restrições. A economia constitucional é responsável pelo estudo no nível analítico pré-constitucional, em que se comparam os resultados dos diferentes arcabouços institucionais 9 .

A economia constitucional é utilizada para a realização de análises institucionais comparativas (Brennan; Buchanan, 1985; Boettke; Palagashvili, 2014; Kirchgässner, 2015). Para Buchanan, o economista deveria avaliar qual a plataforma institucional que melhor permita a convivência social pacífica e cooperativa.

Foi com esse nível analítico em mente que Buchanan propôs a opção teóricometodológica de adoção do homem econômico, para que se possa compreender o resultado, no nível pós-constitucional, da escolha por diferentes arcabouços institucionais no nível préconstitucional. Como afirma Wagner, "[f]or Buchanan, a clear understanding of postconstitutional politics is necessary for guiding constitutional reforms to achieve normative goals" (Wagner, 1987, p. 15).

Boettke explica:

Buchanan emphasizes that we must distinguish between pre- and post-constitutional levels of analysis. Pre-constitutional analysis examines concerns the rules of the game, while post-constitutional analysis examines the strategies players adopt within a set of defined rules. Political economy, properly understood, involves moving back and forth between these two levels (Boettke, 1998, p. 26).

Na perspectiva oferecida por Buchanan (e.g. Brennan; Buchanan, 1985, prefácio), o foco de atenção dos economistas, e dos cientistas sociais em geral, deveria estar sobre a possibilidade de coexistência pacífica entre os indivíduos que agem em busca do interesse próprio que geralmente são conflitantes, de modo a se superar o dilema hobbesiano entre a vida "desagradável, bruta e curta" do mundo anárquico da guerra permanente, ou "desagradável, bruta e escravizada" sob o comando do soberano totalitário. Uma saída possível para o dilema reside na esperança do aperfeiçoamento moral do homem. Muito esforço e energia têm sido despendidos em busca dessa solução, observam os autores.

A outra forma de se solucionar o dilema social de que falaram Brennan e Buchanan (1985, prefácio) parte da constatação de que as pessoas estão longe de possuírem o caráter moral requerido para viverem em harmonia sem a existência de regras de comportamento. Buscar-se-ia, então, na existência de regras que impõem restrições à ação individual, o mecanismo que permite a existência de ordem social. Os autores remeteram à "grande descoberta intelectual do século dezoito" e, em especial, de Adam Smith, de que se houver um

(9) Na economia de Buchanan, constituição é o termo usado para a plataforma de regras acordada anteriormente ao início das ações características do processo econômico e social; é, por assim dizer, o conjunto de regras do jogo combinadas antes de o jogo começar. O exemplo que Buchanan e Tullock (1962, prefácio) deram é o de um prefácio para um livro escrito de forma conjunta: no prefácio estão descritos o método, os pressupostos e os objetivos do livro pactuados antes de os trabalhos começarem, de modo que cada autor separadamente saiba o que deve realizar para a consecução do objetivo comum. 
apropriado aparato legal e institucional, a ação individual, mesmo que permeada por desejos e intenções que não sejam propriamente benevolentes ou fraternas, poderia promover o bem público. Vale dizer, ao buscar seu próprio interesse, o indivíduo, se agir conforme regras adequadas, pode atender também o interesse alheio. Assim, para se promover o bem de outrem, não é necessário que este benefício seja deliberado ou planejado.

Por isso, do ponto de vista do projeto de pesquisa buchaniano, é conveniente que a avaliação do arcabouço institucional aconteça no cenário em que seja mais difícil derivar a convivência harmoniosa em sociedade. Assim, pode-se usar como argumento estratégico o construto teórico do homem econômico com o objetivo de verificar qual o conjunto institucional capaz de converter o pior cenário, qual seja, a sociedade formada por indivíduos puramente egoístas, em um produto benéfico, uma sociedade com alto grau de coordenação e cooperação simbiótica. Nesse sentido, tal estratégia argumentativa adotada por Buchanan é típica da economia política robusta de que falam Pennington (2011), Boettke e Leeson (2004) e Leeson e Subrick (2006): modelar os indivíduos e os agentes públicos e políticos de acordo com o pior cenário possível, o que significa, nesse caso, tratá-los como o homem econômico, e não como benevolentes ${ }^{10}$.

Em outras palavras, o programa de pesquisa de Buchanan em economia constitucional (como explicitado, por exemplo, em Brennan e Buchanan, 1981) é compatível com uma situação em que o homo economicus é adotado como uma ferramenta para a comparação entre arcabouços institucionais no nível analítico que ele chama de pré-constitucional, e não como uma boa referência ontológica capaz de descrever bem o comportamento humano, ou ainda como meio de se atender à usual aspiração por precisão nas predições sobre o comportamento individual, entendida como postura científica (Kirchgässner, 2014).

Na perspectiva defendida por Buchanan e seus seguidores (e.g. Brennan; Buchanan, 1981), ao invés de servir à construção de predições pretensamente científicas e exatas, o homem econômico é apropriado para que o economista possa avaliar comparativamente as diferentes estruturas institucionais que sirvam à coordenação dos diversos participantes da sociedade, já que, para a perspectiva na economia política constitucional de Buchanan (e.g.

(10) Pennington (2011), Boettke e Leeson (2004) e Leeson e Subrick (2006) propõem que uma economia política robusta é aquela em que o sistema econômico utilizado pelo teórico econômico permanece apresentando qualidades desejadas mesmo quando o pior cenário é adotado. Assim, o economista pode trabalhar com um cenário em que as hipóteses conduzam de maneira, em certo sentido, mais fácil aos resultados desejados, ou em um cenário em que os postulados "ideais" não sejam encontrados. Segundo aqueles autores, ao assumir hipóteses como conhecimento e racionalidade perfeitos, mercados completos e preços flexíveis, é possível derivar de maneira, em certo sentido, relativamente fácil o resultado de que o sistema de mercado alcança resultados procurados como, por exemplo, market clearing e um alto grau de coordenação. No entanto, alguns economistas decidem trabalhar longe daqueles postulados, e, mesmo assim, seus sistemas teóricos se mostram robustos a ponto de permanecerem produzindo resultados desejados. Destaque é dado a dois casos que enfatizam as virtudes do regime de mercado: a existência de indivíduos ignorantes ao invés de oniscientes e a solução de mercado para o problema do conhecimento, como na construção teórica associada a Hayek, e os gestores de políticas públicas egoístas ao invés de benevolentes numa plataforma em que há o crescimento do tamanho e do escopo do Estado, produzindo resultados piores em comparação com um regime em que o Estado tem papel reduzido no sistema econômico, como na obra de J. M. Buchanan, conforme será visto adiante. 
Os usos do individualismo por James Buchanan

1994), a teoria econômica não deveria se preocupar em oferecer predições precisas sobre o comportamento individual maximizador.

Por isso Boettke e Coyne (2005) entendem a adoção do homem econômico por Buchanan como uma estratégia de modelagem para o desenho constitucional. A adoção de tal estratégia está relacionada à interpretação de que o papel da economia é justamente compreender como é possível que diversas pessoas convivam de forma coordenada num regime de divisão do trabalho e divisão do conhecimento, ainda que não exista um comando central.

Deste ponto de vista, o economista, desde Adam Smith, deve buscar entender qual o melhor arcabouço institucional que possa promover a conversão do interesse próprio em benefícios alheios, até porque o funcionamento da mão invisível smithiana não se dá numa espécie de "vácuo institucional"11. Assim, partir do pressuposto de que as pessoas não sejam auto-interessadas não seria a melhor estratégia para se entender de que modo se pode estabelecer a convivência harmoniosa entre os diversos indivíduos, de maneira a se resolver o dilema hobbesiano entre a vida curta e livre e a vida longa e escravizada (Brennan; Buchanan, 1985, prefácio). Alguém que procure atender aos desejos e anseios de seus semelhantes muito possivelmente conseguirá produzir o bem alheio; nisto não há grande dificuldade para o estudioso da sociedade. O problema econômico surge exatamente em se descobrir como se pode garantir que o bem comum seja trazido à tona mesmo com indivíduos egoístas, um caso extremo. Daí Boettke e Coyne (2005) argumentarem que a adoção do homem econômico, sob este ponto de vista, faz parte do esforço de se estabelecerem regras que protejam diante do "pior cenário".

Brennan e Buchanan explicaram sua aplicação do homem econômico:

One calls forth the Homo economicus assumption, not because it is necessarily the most accurate model of human behaviour but because it is the appropriate model for testing whether institutions serve to transform private interest into public. It is as simple as that (Brennan; Buchanan, 1981, p. 81).

Aí reside a necessidade estratégica da existência do homem econômico na perspectiva buchaniana. Ao invés de procurar predizer o comportamento, ele é um instrumento para que se busque cumprir o propósito que Adam Smith procurava ter ao dar explicações do tipo "mão invisível" e enfatizar a "alquimia" (na expressão de Brennan; Buchanan, 1981) promovida pelo mercado. De fato, segundo os autores, deveria ser esse o entendimento do uso do homem econômico pela economia política clássica: "[t]he central contribution of the eighteenthcentury philosophers lay in their demonstration that, even under strictly Homo economicus

(11) Santos e Bianchi (2007) explicam, sobre a visão smithiana, que "a realização dos resultados benéficos ou perversos da busca individual do auto-interesse dependerá do conjunto de restrições institucionais sob o qual os indivíduos operam (...). $\mathrm{O}$ argumento institucional, em suma, não apenas indica a não inevitabilidade da mão invisível, como também seu caráter contingente ao ambiente institucional" (Santos; Bianchi, 2007, p. 659, grifos no original). 
assumptions about behaviour, public interest is served by the market order" (Brennan; Buchanan, 1981, p. 84).

Pode-se interpretar o uso do homem econômico na economia de Buchanan como útil em particular na avaliação da capacidade que certos tipos de arcabouço institucional e organização estatal apresentam de atuar de maneira positiva sobre a realidade econômica. Ao menos duas maneiras pelas quais o homem econômico contribuiu para a construção teórica buchaniana podem ser pensadas: o problema dos déficits crônicos e o problema do rent seeking.

\subsection{O homem econômico e o problema da tendência aos déficits crônicos em Buchanan}

Uma maneira pela qual a adoção do homem econômico por Buchanan foi importante para sua contribuição à economia se relaciona com o problema da tendência à existência de permanentes e crescentes déficits públicos, tendência esta identificada por Buchanan com a soberania, no campo tanto da teoria quanto da política econômicas, do keynesianismo e, mais especificamente, da teoria das finanças funcionais.

O próprio Buchanan, ao refletir sobre sua trajetória intelectual, explicou que, em sua interpretação, o avanço das teorias keynesianas e suas propostas de política econômica tinham por pressuposto a ideia de que os agentes públicos seriam preocupados com o bem da população, com a felicidade geral ou com o interesse nacional. Em suma, nessa perspectiva eles seriam benevolentes. Em suas palavras:

The whole of Keynesian and post-Keynesian theory of macroeconomic management (including monetarism) depends critically on the presumption that political agents respond to considerations of "public interest" rather than to the incentives imposed upon them by constituents. Once these agents are modelled as ordinary persons, the whole policy structure crumbles. This basic public-choice critique of the Keynesian theory of policy was presented in Democracy in Deficit, written jointly with Richard E. Wagner (Buchanan, 1986a, p. 20-21).

A estratégia argumentativa adotada por Buchanan, por outro lado, pode ser vista passando, como discutido anteriormente, por modelar os agentes públicos e políticos de acordo com o pior cenário possível, o que significa, nesse caso, tratá-los como o homem econômico, e não como benevolentes.

Em seu livro Democracy in Deficit, Buchanan e Wagner (1977) procuraram discutir a pretensa existência de políticos benevolentes, bem como de economistas ditando de forma fria e racional os rumos que a política econômica deveria tomar, em particular o tratamento dos gastos do governo simplesmente como uma variável exógena nos modelos. A contribuição pretendida pelos autores foi mostrar que, ao abrir mão de tais postulados e tratar políticos e economistas de acordo com o pior caso, o egoísmo, esse modelo de gestão econômica acabaria por se mostrar não tão atraente quanto antes. Isso se deve a que a política econômica keynesiana efetuada nos EUA especialmente entre as décadas de 1940 e 1970, passou a apresentar, sob o ponto de vista da public choice e da constitutional economics, uma espécie de viés deficitário, 
na medida em que, na visão ora apresentada, haveria uma espécie de falha constitucional. Isso geraria incentivos ao endividamento que permitiria tanto aumentar os gastos da administração atual - o que levaria ao aumento imediato do crescimento econômico - quanto impor um limite à liberdade de gasto da administração futura.

Em outras palavras, ao contrário do keynesianismo e, em particular, da teoria das finanças funcionais, na perspectiva oferecida por Buchanan, o político preferiria tomar decisões que the rendessem dividendos políticos como, por exemplo, manter de forma persistente gastos elevados e tributos baixos, de maneira a garantir emprego e produção em níveis altos e, possivelmente, deixar seu sucessor com espaço limitado de ação, especialmente se for de um grupo político rival. Por isso, dar poder discricionário ao agente público na esperança de que, em busca do bem geral, ele saiba o que fazer e deseja fazê-lo, não deveria ser admitido. Aceitar a benevolência do político, sob tal ponto de vista, é uma hipótese por demasiado restritiva.

Nesse sentido, um sistema que possui uma apropriada estrutura institucional seria robusto na medida em que, mesmo que adotado o pior cenário para a motivação do político, ele permanecesse produzindo resultados desejados. Isso, na visão de Buchanan e seus pares, não aconteceria, por exemplo, com o keynesianismo democrático e a teoria das finanças funcionais.

Sob tal ângulo, o construto teórico da economia constitucional, em particular no Democracy in Deficit, combina com dois princípios que perpassaram a obra de Buchanan.

Em primeiro lugar, a visão de que a economia deva ser uma ciência pública (Buchanan, 1962) no sentido de possuir um papel pedagógico importante de esclarecimento dos estudantes e da população em geral, bem como que a distinção entre economia positiva e normativa é, em certo sentido, enganadora.

Em segundo lugar, que não se deve confiar na benevolência e no conhecimento neutro dos políticos e dos economistas que os auxiliam, tampouco em sua discricionariedade, mas sim enfatizar instituições que forneçam previamente as regras do jogo, que limitem a ação estatal, que informem os agentes e que convertam o vício privado em benefício público. A partir da ideia de que "os políticos também são auto-interessados" - a "política sem romance" (Buchanan, 1979) - surgem duas das "batalhas" de Buchanan em questões de política econômica: a constitucionalização da política monetária (Buchanan, 2010) e do equilíbrio no orçamento público (Buchanan; Wagner, 1977).

\subsection{O homem econômico e o problema de rent seeking em Buchanan}

Uma segunda consequência do uso do homem econômico na economia de Buchanan é a contribuição deste autor ao estudo do problema de rent seeking (e.g. Buchanan, 1980). De acordo com Buchanan, o crescimento do tamanho e do escopo da ação estatal, em particular 
nos EUA no período seguinte ao New Deal até a década de 1970, gerou problemas desse tipo em diversos setores da economia.

Na perspectiva oferecida por Buchanan, valendo-se explicitamente de uma abordagem de processo de mercado associada a Israel Kirzner, rent seeking é uma espécie de comportamento desvirtuado por parte do indivíduo que busca seu interesse e que prefere mais a menos. Nessa situação, a ação típica do processo concorrencial de mercado em busca da exploração de oportunidades de ganho seria desviada para a garantia da manutenção de um privilégio que crie uma escassez artificial e, daí, uma renda, ou então a atuação em mecanismos fora do mercado para que tais privilégios sejam alcançados por outro agente. Se prevalecesse a condição de livre entrada em determinado mercado, o processo competitivo acabaria por levar à extinção daquela renda adicional. Ou seja, rent seeking é o profit seeking convencional, mas num ambiente institucional inapropriado, em que podem existir barreiras à entrada, escassez artificialmente criada e oportunidades de ganhos que não podem ser exploradas ${ }^{12}$.

Com rent seeking, recursos escassos seriam direcionados não àqueles setores que apresentam renda como sinal de mercado de escassez relativa elevada, mas sim no convencimento da autoridade pública de que se deve manter a barreira, se o agente for o beneficiado, ou então eliminá-lo ou dividi-lo, se estiver de fora. Ou seja, como a escassez e as rendas permanecem, o sinal de mercado que indica a conveniência de investimento naquela determinada atividade também permanece, o que leva à existência de diferentes formas de se tentar capturar a renda que não o comportamento competitivo.

Para os propósitos deste artigo, o mais importante na análise de Buchanan de rent seeking é que a avaliação do crescimento da ação estatal e de seu escopo pode ser associada ao tipo de suposição acerca da motivação dos indivíduos. Buchanan (1980) assumiu o caso em que os indivíduos são auto-interessados e desejam mais a menos, e, por isso, não se preocupam com conceitos como preço justo, concorrência leal e atuação ética - e isso não toma a forma de comportamento normativo ou constatação empírica, mas sim como ferramenta para uma análise institucional comparativa.

Assim, ao assumir um tipo de motivação do agente econômico, a conclusão tirada a partir de Buchanan (e.g. 1980) é que, para o mesmo tipo de agente, o do pior cenário (homo economicus), um tipo de plataforma institucional, aquela associada ao livre mercado, seria capaz de gerar resultados desejados (coordenação, crescimento econômico, redução da escassez, criação de valor, bom aproveitamento de recursos, etc.) como consequência não intencional da ação humana. Uma mudança institucional marcada pelo aumento do Estado e de seu escopo e, assim, pelo bloqueio do processo de mercado, porém, teria como consequência

(12) Buchanan (1980), a rigor, falou de ao menos dois tipos de rent seeking. O primeiro, que é o tratado aqui, refere-se à situação em que o Estado bloqueia a entrada de novos ofertantes, o que faz com que o preço permaneça mais alto que o existente caso o cenário competitivo prevalecesse, e em que permanecem as rendas. Já o segundo caso de rent seeking é aquele em que a intervenção conduz à manutenção do preço abaixo do que seria o resultado do processo de mercado competitivo através do bloqueio à entrada de novos demandantes. 
Os usos do individualismo por James Buchanan

não-intencional a perda daqueles bons resultados, por levar ao comportamento de tipo rent seeking que não conduz à redução da escassez e ao aumento da coordenação, mas sim ao desperdício de recursos.

\section{Buchanan e a defesa da sociedade liberal: o individualismo normativo e o contratualismo}

A adoção do individualismo em Buchanan também está vinculada a outro aspecto que o afastava da economia convencional: a aceitação do aspecto normativo da economia que, como dito anteriormente, caracterizou a obra de Buchanan e a sua forma de argumentar em prol do liberalismo.

Diante disso, de que maneira a visão particular assumida por Buchanan, crítica da economia convencional, relacionava-se com a defesa da sociedade liberal individualista por parte do norte-americano?

Os economistas usualmente apregoam o individualismo, entendido como liberalismo, enquanto modo ideal de funcionamento da sociedade. Se forçados a pensar no fundamento dessa defesa, de acordo com Buchanan (1991), os economistas se inclinarão para um individualismo epistêmico, que apregoa que o indivíduo (ou o que anteriormente foi classificado como homem econômico de tipo lógico) deve ser livre porque dispõe de conhecimento privilegiado para decidir o que é melhor para si mesmo. Ainda segundo Buchanan (1991), tal argumento é consequência da existência, na teoria microeconômica, de um mapa de curvas de indiferença que refletem a disposição do indivíduo em trocar certa cesta de bens por outra, sem que se altere a utilidade derivada da sua fruição. Ao escolher determinada cesta de bens o indivíduo maximiza sua utilidade, dadas as restrições naturais, orçamentárias, institucionais, etc. Na interpretação usual dos economistas, diz Buchanan (1991), a utilidade, ou o quer que seja que o indivíduo maximize, é algo que existe de fato na mente da pessoa de modo independente da própria escolha; a escolha, em certo sentido, é automática, na medida em que as preferências estão dadas na mente do indivíduo, e as restrições são colocadas pelo estado de mundo. Com isso, torna-se, a princípio, possível julgar se a escolha feita pelo indivíduo é correta - se ela maximiza a função utilidade dadas as restrições existentes.

Buchanan (1991) prossegue explicando que o individualismo normativo epistêmico está baseado nessa ontologia em que a utilidade possui uma existência por si mesma, analiticamente anterior, separada e independente do processo de decisão e escolha. Nessa concepção, o individualismo normativo se baseia na suposição de que o indivíduo dispõe do privilégio de saber melhor do que qualquer um qual é, digamos, a função utilidade que está em sua mente, e que o modo de organização social e as instituições típicas de uma sociedade liberal são desejáveis justamente por aumentarem bastante o leque de possibilidades de escolha individual, de maneira que seja aproveitada essa vantagem epistêmica.

Essa defesa epistêmica da sociedade liberal individualista é, no entanto, insuficiente, argumentou Buchanan (1991). Ele fala de ao menos três objeções que se levantam: a do 
Eduardo Angeli

paternalismo benevolente, que argumenta que o indivíduo, por possuir conhecimento limitado, não sabe o que é melhor para si, ao menos não tanto quanto experts educados e treinados; a do socialismo científico, que desloca a ênfase sobre a decisão individual para dar importância ao destino coletivo e aos valores sociais que existem independentemente dos indivíduos; e, finalmente, o idealismo político, que entende que instituições que ampliem as possibilidades de escolha individual podem levar ao comportamento primitivo, bárbaro, animalesco, privilegiando, então, a existência de instituições que valorizem e promovam a ação individual conforme critérios éticos, metafísicos ou estéticos pré-definidos.

Buchanan (1991) afirmava não concordar com a ontologia em que há uma função utilidade independente da própria escolha, apenas à espera da restrição objetiva para fornecer o ponto que o indivíduo deve expressar preferência. Ao contrário: o que existe, disse ele, são apenas as escolhas feitas pelos indivíduos, e é sobre elas que os economistas devem teorizar. Não existiria, por assim dizer, um privilégio epistêmico que garanta ao indivíduo maior conhecimento de sua própria função utilidade, assim como não é possível julgar como corretas ou não, segundo algum critério de maximização ou conforme conhecimento posterior, as preferências manifestadas por ele. O indivíduo que escolhe se insere num processo de interação de diversos agentes entre si e com a natureza ao longo do tempo, processo de retroalimentação que faz surgirem restrições, limites e conhecimento novo importantes à ação e à própria escolha individual.

Dessa forma, o individualismo liberal normativo de Buchanan está assentado não sobre o conhecimento da própria função utilidade por parte do indivíduo, mas sim sobre sua posição (contratualista) acerca da origem do poder a partir exclusivamente dos indivíduos. Em sua perspectiva, eles são os soberanos sobre a questão de qual forma de organização política e social viverão, e é a partir deste princípio, da adesão e aprovação por parte dos indivíduos, que a legitimidade dos corpos institucionais em sentido amplo deve ser avaliada. Como se sabe, sua abordagem constitucionalista foi classificada pelo próprio Buchanan como adepta da visão contratualista - ainda que o contrato social fosse entendido por ele como uma metáfora para legitimar e guiar o futuro, e não como um fato historicamente verdadeiro:

Our position is explicitly and avowedly contractarian (...). To counter the most familiar and pervasive criticisms of this position, we must note that the contractarian construction itself is used retrospectively in a metaphorically legitimizing rather than historical sense. Prospectively, the model is used in both a metaphorically evaluative and an empirically corroborative sense (Brennan; Buchanan, 1985, p. 23).

A adesão ao contratualismo foi explicada por Buchanan e Tullock (1962, caps. 1 e 2) como a saída intelectual utilizada para se evitar o problema de regressão infinita - como escolher a regra que será utilizada para escolher as regras? Nesse caso, deveria se partir do pressuposto (não necessariamente embasado na realidade histórica) de que a "constituição" (o arcabouço de regras inicial) é construída a partir do critério de decisão por unanimidade entre os indivíduos. Assim, seria garantida uma fórmula segundo a qual a constituição promoveria a melhoria da situação de todos os indivíduos, sem a necessidade de se recorrer a construções 
Os usos do individualismo por James Buchanan

como "interesse nacional" ou "dominação de classe". O critério, portanto, está assentado sobre a decisão individual acerca de qual postura tomar diante de determinada regra constitucional proposta, que será apoiada apenas se for entendida pelo indivíduo como benéfica ou indiferente. Nesse sentido, existe uma "Paretian norm for political economy. In the preconstitutional moment, no bargain concerning the rules of the game would be agreed to unless all parties expected to be made better off by adopting the rules in question" (Boettke, 1998, p. 33).

\section{Considerações finais}

O ensaio interpretou o papel do individualismo e do homo economicus no pensamento econômico de Buchanan. Transpareceu, em primeiro lugar, que o uso do homem econômico por James Buchanan é compatível com uma perspectiva diferente do que é o usual em Economia e, em segundo lugar, que subjacente a tal distinção está uma postura crítica tomada por ele perante o que a maior parte da profissão entende como o escopo da Economia e o papel do profissional. Para Buchanan, a análise institucional comparativa deveria estar no centro das atenções do economista e, para isso, o uso do homem econômico é uma estratégia conveniente. Isso porque ele permite a avaliação teórica de diferentes arcabouços institucionais que possibilitam a convivência harmoniosa e a cooperação social (não-intencional) diante do pior cenário em termos de motivação dos indivíduos. A partir disso, foi mostrado que a adoção da hipótese do homem econômico por Buchanan foi um elemento central na sua compreensão dos problemas de rent seeking e da tendência aos déficits públicos, movimentos associados por ele à ampliação do escopo e do tamanho do Estado, especialmente entre as décadas de 1940 e 1970. Por fim, foi discutido como a adesão ao individualismo por Buchanan não implicava uma defesa epistêmica da sociedade liberal individualista, como, a princípio, é feito pela maior parte dos economistas, mas sim que o norte-americano associava a defesa de tal sociedade a sua abordagem contratualista ligada à Constitutional Economics.

Ao propor contribuir com o esclarecimento de alguns aspectos metodológicos da obra de Buchanan, o presente artigo foi ao encontro de um esforço de interpretação e sistematização da sua obra que vem sendo levado adiante atualmente, especialmente após a morte de Buchanan. A importância disso se torna mais evidente quando se tem em mente a extensão da obra de Buchanan. Os Collected Works de Buchanan totalizam vinte volumes. A coleção foi publicada entre 1999 e 2002, onze anos antes da morte do autor, que continuou produtivo até o fim de sua vida. O currículo de Buchanan, publicado no volume 20 dos Collected Works (Buchanan, 2002), traz 45 páginas de referências bibliográficas referentes a suas publicações.

Destaque-se, neste movimento recente, os trabalhos de Kogelmann (2015), Kirchgässner (2014), Wagner (2014), Den Uyl (2014) e Boettke e Palagashvili (2014). Em certo sentido, tais pesquisas continuam o trabalho que o próprio Buchanan havia iniciado de expor e refletir sobre sua trajetória, as influências recebidas e os postulados e propósitos de suas contribuições, como, por exemplo, em Buchanan (1986a, 1990, 1992a, 1992b, 2012). 
Eduardo Angeli

\section{Referências bibliográficas}

BLAUG, M. (1992). A metodologia da economia, ou como os economistas explicam. São Paulo: Edusp, 1999.

BOETTKE, P. J. James M. Buchanan and the rebirth of political economy. In HOLT, R., PRESSMAN, S. (Org.). Economics and its discontents: twentieth century dissenting economists. Aldershot: Edward Elgar, 1998.

BOETTKE, P. J.; COYNE, C., James M. Buchanan (1919-). In: KRIER, D.; VAN DELINDER, J. (Org.). Dictionary of modern American philosophers. Bristol: Thoemmes Press, 2005.

BOETTKE, P. J., LEESON, P. T. 2004. Liberalism, socialism, and robust political economy. Journal of Markets and Morality, v. 7, n. 1, p. 99-111, 2004.

BOETTKE, P. J.; PALAGASHVILI, L. James Buchanan's contributions to constitutional political economy, institutional analysis, and self-governance. Journal of Law, Economics \& Policy, v. 10, n. 3, p. 649-667, 2014.

BOETTKE, P. J.; MARCIANO, A. The past, present and future of Virginia political economy. Public Choice, v. 163, n. 1, p. 53-65, 2015.

BRENNAN, G., BUCHANAN, J. M. (1981). The normative purpose of economic 'science': rediscovery of an eighteenth century method. In: BUCHANAN (2000).

BRENNAN, G., BUCHANAN, J. M. (1985). The reason of rules: constitutional political economy. Indianapolis: Liberty Fund, 2000. (The Collected Works of James M. Buchanan, v. 10).

BUCHANAN, J. M. (1949). The pure theory of government finance: a suggested approach. In: BUCHANAN (1999).

BUCHANAN, J. M. (1962). Economics as a public science. In: BUCHANAN (2000).

BUCHANAN, J. M. (1964). What Should Economists Do? In: BUCHANAN (1999).

BUCHANAN, J. M. (1969). Is Economics the Science of Choice? In: BUCHANAN (2000).

BUCHANAN, J. M. (1979). Politics without romance: a sketch of positive public choice theory and its normative implications. In: BUCHANAN (1999).

BUCHANAN, J. M. (1980). Rent seeking and profit seeking. In: BUCHANAN (1999).

BUCHANAN, J. M. (1986a). Better than plowing. In: BUCHANAN (1999).

BUCHANAN, J. M. (1986b). Political economy: 1957-82. In: BUCHANAN (2001).

BUCHANAN, J. M. (1986c). The constitution of economic policy. In: BUCHANAN (1999).

BUCHANAN, J. M. (1990). Born-again economist. In: BUCHANAN (2001). 
Os usos do individualismo por James Buchanan

BUCHANAN, J. M. (1991). The foundations for normative individualism. In: BUCHANAN (1999).

BUCHANAN, J. M. (1992a) From the inside looking out. In: BUCHANAN (2001).

BUCHANAN, J. M. (1992b). Italian retrospective. In: BUCHANAN (2001).

BUCHANAN, J. M. (1992c). Virginia political economy. In: BUCHANAN (2001).

BUCHANAN, J. M. (1994). Economic theory in the postrevolutionary moment of the 1990s. In: BUCHANAN (2000).

BUCHANAN, J. M. The logical foundations of constitutional liberty. Indianapolis: Liberty Fund, 1999. (The Collected Works of James M. Buchanan, v. 1).

BUCHANAN, J. M. Economic inquiry and its logic. Indianapolis: Liberty Fund, 2000. (The Collected Works of James M. Buchanan, v. 12).

BUCHANAN, J. M. Ideas, persons, and events. Indianapolis: Liberty Fund, 2001. (The Collected Works of James M. Buchanan, v. 19).

BUCHANAN, J. M. Indexes. Indianapolis: Liberty Fund, 2002. (The Collected Works of James M. Buchanan, v. 20).

BUCHANAN, J. M. The constitutionalization of money. Cato Journal, v. 30, n. 2, p. 251-258, 2010.

BUCHANAN, J. M. Genesis. Public Choice, v. 152, n. 3-4, p. 253-255. 2012.

BUCHANAN, J. M., TULLOCK, G. (1962). The calculus of consent: logical foundations of constitutional democracy. Indianapolis: Liberty Fund, 2004. (The Selected Works of Gordon Tullock, v. 2).

BUCHANAN, J. M., WAGNER, R. (1977). Democracy in deficit: the political legacy of Lord Keynes. Indianapolis: Liberty Fund, 2000. (The Collected Works of James M. Buchanan, v. 8).

CERQUEIRA, H. E. G. Para ler Adam Smith: novas abordagens. Síntese, v. 32, n. 103, p. 181$202,2005$.

COLANDER, D. Functional finance. In: GLASNER, D. (Org.). Business cycles and depressions: an encyclopedia. Oxon: Routledge, 1997.

DEN UYL, D. J. Natura naturans, natura naturata. Review of Austrian Economics, v. 27, n. 2, p. 175-182, 2014.

FONSECA, E. G. Comportamento individual: alternativas ao homem econômico. Estudos Econômicos, v. 20, n. especial, p. 5-37, 1990.

HARGREAVES-HEAP, S. Economic man. In: DURLAUF, S. N.; BLUME, L. E. (Org). The New Palgrave Dictionary of Economics. 2nd. ed. Hampshire: Palgrave Macmillan. 2008. v. 2. 
Eduardo Angeli

KIRCHGÄSSNER, G. The role of homo oeconomicus in the political economy of James Buchanan. Constitutional Political Economy, v. 25, n. 1, p. 2-17, 2014.

KIRZNER, I. M. (1960). The economic point of view. Indianapolis: Liberty Fund, 2009. (The Collected Works of Israel M. Kirzner).

KOGELMANN, B. Modeling the individual of constitutional choice. Constitutional Political Economy, v. 26, n. 4, p. 455-474, 2015.

LEESON, P.; SUBRICK, J. R. Robust political economy. Review of Austrian Economics, v. 19, n. 2-3, p. 107-111, 2006.

MATTOS, L. V. Transformando 'verdades abstratas' em 'verdades concretas': uma análise sobre a metodologia econômica de John Stuart Mill. Estudos Econômicos, v. 34, n. 1, p. 101$125,2004$.

MEDEMA, S. G. The hesitant hand: taming self-interest in the history of economic ideas. Princeton: Princeton University Press, 2009.

PENNINGTON, M. Robust political economy: classical liberalism and the future of public policy. Cheltenham: Edward Elgar, 2011.

ROBBINS, L. The nature and significance of economic science. London: MacMillan \& Co., 1932.

SANTOS, A. T. L. A.; BIANCHI, A. M. Além do Cânon: mão invisível, ordem natural e instituições. Estudos Econômicos, v. 37, n. 3, p. 635-662, 2007.

SEN, A. Rational fools: a critique of the behavioral foundations of economic theory. Philosophy and Public Affairs, v. 6, n. 4, p. 317-344, 1977.

SEN, A. On ethics and economics. Malden: Blackwell, 1988.

WAGNER, R. E. James M. Buchanan: constitutional political economist. Regulation: AEI. Journal on Government and Society, v. 11, n. 1, p. 13-17, 1987.

WAGNER, R. E. Public choice as an academic enterprise: Charlottesville, Blacksburg, and Fairfax retrospectively viewed. American Journal of Economics and Sociology, v. 63, n. 1, p. 55-74, 2004.

WAGNER, R. E. James Buchanan's public debt theory: a rational reconstruction. Constitutional Political Economy, v. 25, n. 1, p. 253-264, 2014. 